\title{
Evaluation and Measurement in Data Science in Medical Science and Healthcare
}

\author{
Mauliza, Sulistyo Andarmoyo, Nurmiati Muchlis, K. Shankar, Phong Thanh Nguyen
}

\begin{abstract}
In the system of healthcare functioning well the data is very important factor. In the countries around the globe in the development of infrastructures of data over the past few years the huge strides have been made. To promote better health outcomes and to improve programs on the need to use this data the global health professionals place enhancing the pressure. Across the planet to support health systems to emphasis on data is emerging like a huge source of available data. It can say as the tsunami of data in both extent and scope. Due to sheer scale of this massive wave of information it is a challenging task to improve public health and support.
\end{abstract}

Keywords- healthcare, data, global health, improve programs

\section{INTRODUCTION}

From the large amount of data find, use and communicate the useful information is known as data science process. By health systems to expand the insights yielded and to strengthen in the world the use of ever-growing amount of data make it possible [1-3].

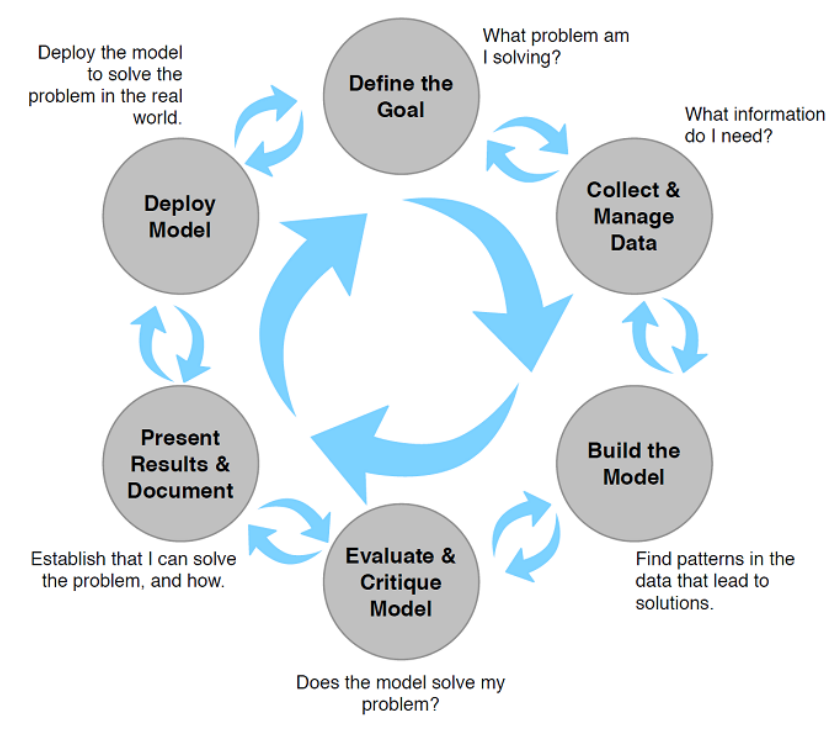

Figure 1: Data Science Process

From non-traditional sources like mobile phone, routine health information systems (RHIS) and household surveys the

Revised Version Manuscript Received on 16 September, 2019.

Mauliza, Faculty of Medicine, Universitas Malikussaleh, Indonesia. E-mail: mauliza@unimal.ac.id

Sulistyo Andarmoyo, Universitas Muhammadiyah Ponorogo, Indonesia

Nurmiati Muchlis, Universitas Muslim Indonesia, Indonesia

K. Shankar, Department of Computer Applications, Alagappa University, India. E-mail: shankarcrypto@gmail.com

Phong Thanh Nguyen*, Department of Project Management, Ho Chi Minh City Open University, Vietnam. E-mail: phong.nt@ou.edu.vn
* Correspondence Author

data science use to bring the data together to predict effects of health interventions or model outbreaks of disease. To improve evaluation and monitoring and to strengthen health systems the potential of data science explore by MEASURE Evaluation [4-5].

Promote and exploring the MEASURE Evaluation by using the emerging approach of data science as follows:

1. In global health it show the innovative data science applications by Publishing research

2. In global health for data science best practices identification

3. On data science providing technical assistance

4. Using a data science framework implement a tool that facilitate the communication, management and analysis, of data.

\section{Qualitative AND QUANTITATIVE DATA: MEASUREMENT LEVELS}

This can be categorized into two groups: qualitative data and quantitative data [6].

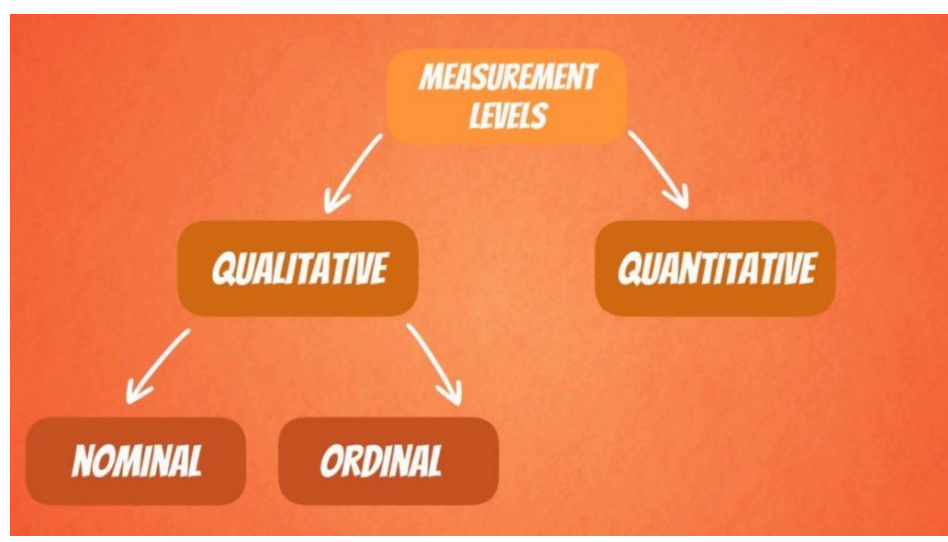

Figure 2: Measurement levels

\section{Qualitative Data}

In nominal and ordinal groups it can further divide the qualitative data.

Like car brands- Audi, Mercedes or BMW it can categories the Nominal variables or such as 4 weathers- summer, winter, autumn and spring. It cannot be ordered and they are not numbers.

Published By:

Blue Eyes Intelligence Engineering 


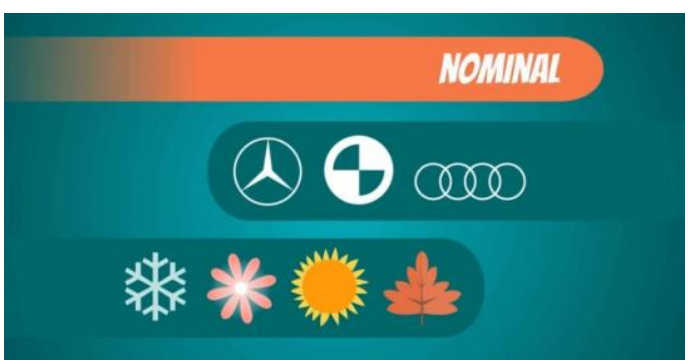

Figure 3: Nominal variables

On the other hand the Ordinal data strictly follows the order and consists of categories and groups. For example if it asks to rate a lunch and it have the options like delicious, unappetizing, disgusting, tasty and neutral. It can give the preferences ordered from negative to positive although we have words not numbers, in this way the measurement level is qualitative, ordinal.

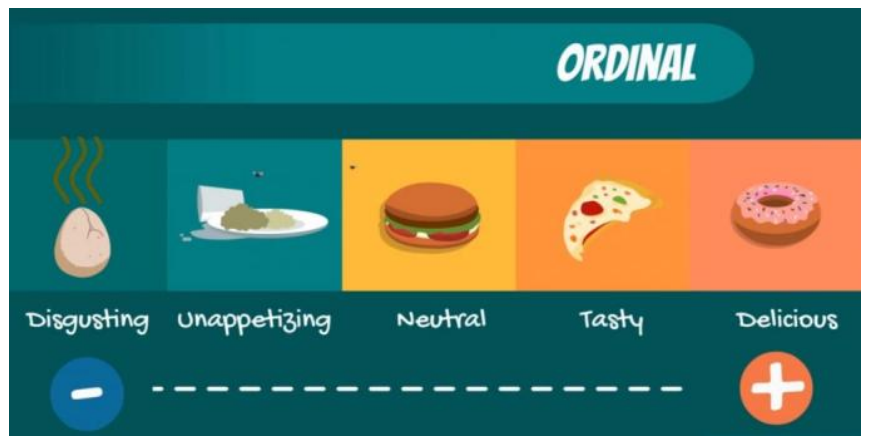

Figure 4: Ordinal variables

\section{Quantitative Data}

Interval and ratio are the two groups in which the quantitative variables are categorized .

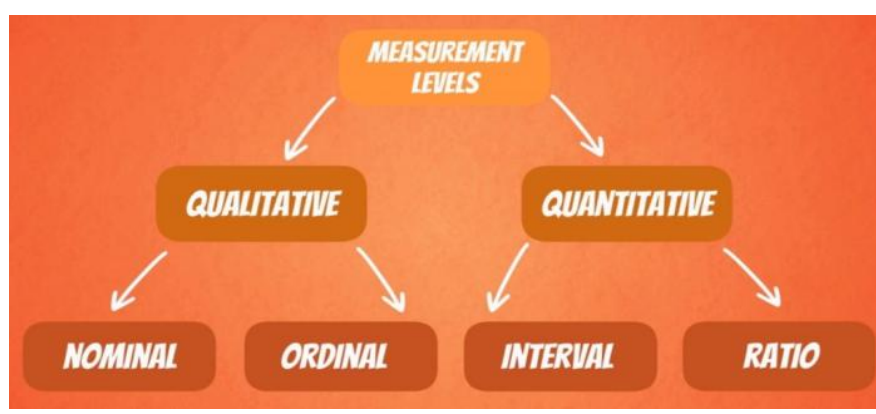

Figure 5: Quantitative data classification

\section{Ratios}

In the real world most things we observe are consider as ratios. They can present the things's ratio on that basis their name comes from.

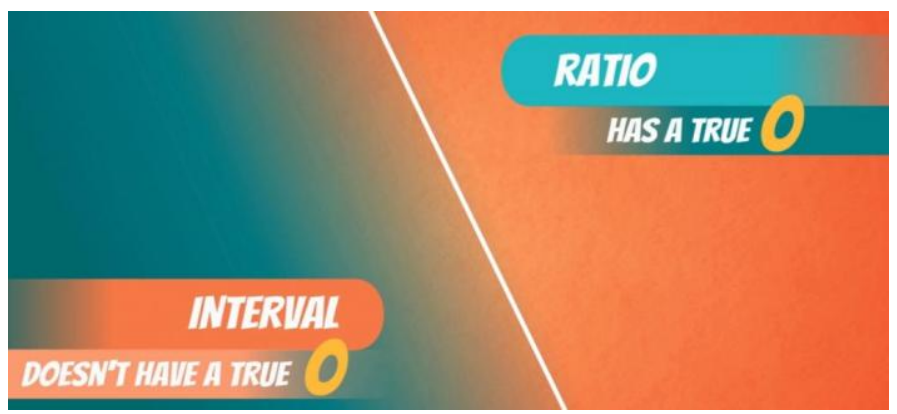

Figure 6: Ratio

\section{Intervals}

The Intervals consider as common aspect. The most common example of an interval variable is Temperature. It doesn't have a true 0 and it can represent a ratio of things.

\section{HealthCare Quality Measures TyPeS}

Measures used to assess and compare the quality of health care organizations are classified as either a structure, process, or outcome measure. Known as the Donabedian model, this classification system was named after the physician and researcher who formulated it.

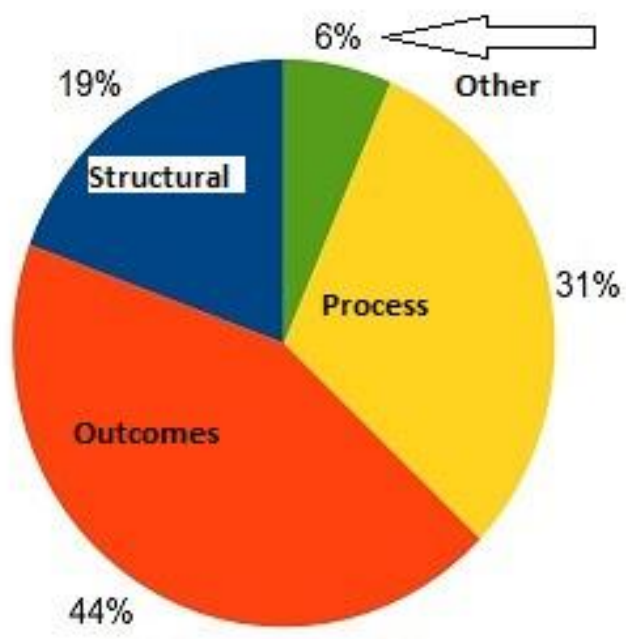

Figure 7: Measuerment of Healthcare Quality [7]

\section{Measures of Structural}

A sense of the processes to provide high-quality care, systems and capacity of health care provider provided by structural measures. As a example:

1. To patients the ratio of providers

2. Medication order entry systems or electronic medical records uses by health care organization.

3. Board-certified physicians's proportion or numbers [8]

\section{Measures of Process}

either for those diagnosed with a health care condition or for healthy people to improve or maintain health

provider what a a provider does is indicated by process measures. For clinical practice these measures typically reflect generally accepted recommendations. For example:

1. With diabetes the people percentage that had controlled and tested the blood sugar.

2. The people percentage that receiving preventive services [9]

\section{Measuring HealthCare Quality}

To leads the improved care and how the health system is performing the quality of healthcare measure and evolution is very necessary. 


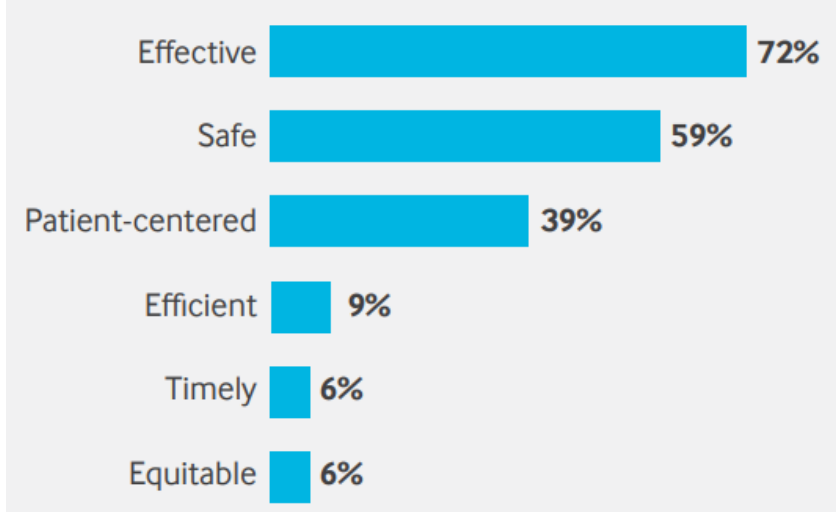

Figure 8: Quality in healthcare Mean [10]

Against the standards of recognized quality data to evaluate the health plans performance in health care the process is using is known as Quality measurement. Across the full range of health care settings these measures can evaluate, from office of doctor to imaging facilities to hospital systems. It can take many types.

\begin{tabular}{|l|l|l|}
\hline TYPE & DESCRIPTION & EXAMPLE \\
\hline Structure & $\begin{array}{l}\text { Assesses the characteristics of a care } \\
\text { setting, including facilities, personnel, } \\
\text { and/or policies related to care delivery. }\end{array}$ & $\begin{array}{l}\text { Does an intensive care unit (ICU) have a } \\
\text { critical care specialist on staff at all times? }\end{array}$ \\
\hline Process & $\begin{array}{l}\text { Determines if the services provided to patients } \\
\text { are consistent with routine clinical care. }\end{array}$ & $\begin{array}{l}\text { Does a doctor ensure that his or her patients } \\
\text { receive recommended cancer screenings? }\end{array}$ \\
\hline Outcome & $\begin{array}{l}\text { Evaluates patient health as a result of the care } \\
\text { received. }\end{array}$ & $\begin{array}{l}\text { What is the survival rate for patients who } \\
\text { experience a heart attack? }\end{array}$ \\
\hline $\begin{array}{l}\text { Patient } \\
\text { Experience }\end{array}$ & $\begin{array}{l}\text { Provides feedback on patients' experiences of } \\
\text { care. }\end{array}$ & $\begin{array}{l}\text { Do patients report that their provider explains } \\
\text { their treatment options in ways that are easy to } \\
\text { understand? }\end{array}$ \\
\hline
\end{tabular}

Table 1: Quality measure types in halthcare [11]

\begin{tabular}{|c|c|c|}
\hline ENTITY & DESCRIPTION & EXAMPLE \\
\hline Health Plan & $\begin{array}{l}\text { Assesses the services provided by the } \\
\text { health plan and the overall performance of } \\
\text { providers in the plan's network. }\end{array}$ & $\begin{array}{l}\text { Does the health plan cover treatment of } \\
\text { alcoholism or other drug dependence? }\end{array}$ \\
\hline Provider & $\begin{array}{l}\text { Assesses the quality of a provider's facilities } \\
\text { and/or the overall quality of care provided. }\end{array}$ & $\begin{array}{l}\text { Does the hospital provide services to treat } \\
\text { alcoholism or other drug dependence? }\end{array}$ \\
\hline $\begin{array}{l}\text { Health Care } \\
\text { Professional }\end{array}$ & $\begin{array}{l}\text { Assesses the quality of care provided by an } \\
\text { individual health care professional. }\end{array}$ & $\begin{array}{l}\text { Did the physician tell the patient that treatment } \\
\text { is available for alcoholism or other drug } \\
\text { dependence? }\end{array}$ \\
\hline
\end{tabular}

Table 2: Evulation of entitty

\section{Measures of Healthcare Outcome}

With regulatory and administrative complexities the industry of healthcare filled that make it hard for wellbeing frameworks to accomplish the Triple-or even better, the Quadruple-Aim of healthcare. The complexities found in results improvement are especially testing, as wellbeing frameworks measure and report on many these results yearly. Wellbeing frameworks can deal with these complexities by investigating result measures-understanding their definitions and subtleties, assessing genuine models, and coordinating three fundamentals for effective outcomes evolution. [12-14]. 
Improve the patient experience of care.

Improve the health of populations.

Reduce the per capita cost of healthcare.

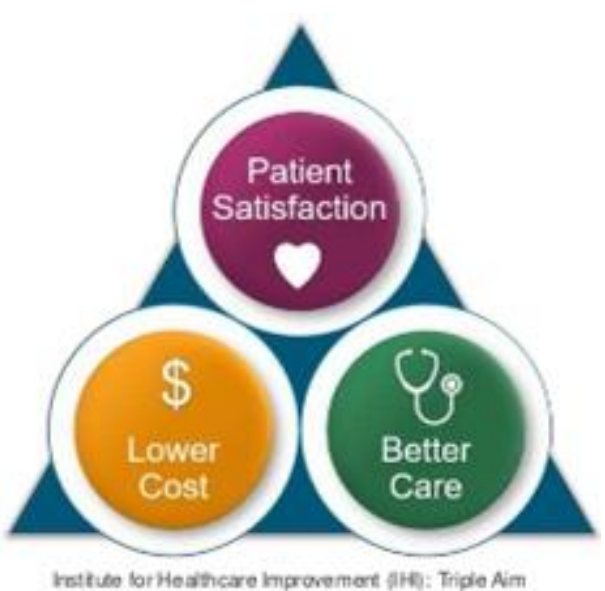

Int tub lor Heashcare improvemart AHe: Triple Aim

Figure 9: Healthcare Outcome Measure

\section{Benefits of Healthcare Outcomes}

To achieve the Quadruple aim of healthacre and medical science the objective of comparing, reporting and measuring healthcare outcomes are:

1. The patient experience of care improvement

2. Staff burnout and clinician reduction

3. Healthcare's per capita cost reduction

4. Health of populations improvement

\section{HEALTH STATUS MEASURES}

By using clinical and pathological measures it can measure the Health status. It is generally measured using instruments or observed by clinicians.

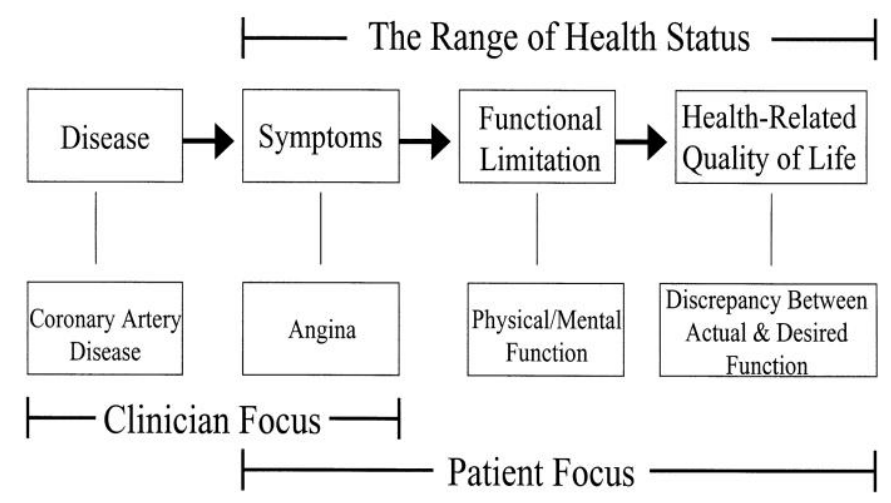

Figure 10: Measure of Health status [15]

\section{The disease measurement types are:}

1. Disease Signs - tumour size, temperature, blood pressure, X-ray,

2. Diease Symptoms - checklists of disease specific

3. Co-morbidity - adverse events - complications, pain, readmission, bleeding, Charlson Index, - index of co-existing disease (ICED),

\section{Practical criteria}

As a part of clinical practice id the measure is intended for routine utilization:

1. To administer the measure should be simple and brief

2. It should be relevant and appropriate
3. For routine use measure should be feasible

The existing measure can be adapt any time, altough for responsiveness, reliability and validity in the new conditions it must be re-evaluated. Else for responsiveness, reliability and validity it need to evaluate and develop a new measure.

The reliability of test can improve by the following factors:

1. Acting on discrepancies and cause identification

2. Review of techniques and Regular observation

3. Protocols, terminology and criteria's clear definition

4. Observers training

To increase validity the following methods are inluded:

1. Well-constructed instruments use

2. Reports of information obtain appropriately

3. For collecting clinical information collection standardised and structured procedures

4. For and interpreting and scoring standardised protocols

\section{MEASURES OF HEALTH CARE}

In Study design for assessing acceptability, effectiveness and efficiency of services and Measures of supply and demand it has been already described the performance measures of healthcare, it incorporate outcome of health care, structure, service quality and process. It may included:

1. Performance of Finance execution is currently viewed as a key part of health care performance.

2. Quality of medicinal services can likewise be estimated regarding process just as results, for example, the execution of rules, most recent proof and criteria for treatment and referral. Likewise quality can be surveyed by outside associations, for example, the Care Quality Commission through their observing and assessment procedures and Monitor.

3. Measurement of patient reported outcome, Patient experience and patient satisfaction. There are many attempted and tried patient reviews in presence to catch fulfillment and experience as utilized by the Care Quality Commission and Picker Institute in national execution checking. 
4. It normally used measures by productivity or Quantity of health care organisations [16].

\section{CONCLUSION}

In the countries around the globe in the development of infrastructures of data over the past few years the huge strides have been made. To promote better health outcomes and to improve programs on the need to use this data the global health professionals place enhancing the pressure. By health systems to expand the insights yielded and to strengthen in the world the use of ever-growing amount of data make it possible. Measures used to assess and compare the quality of health care organizations are classified as either a structure, process, or outcome measure.

\section{REFERENCES}

[1] Aronson, A.R.: Effective mapping of biomedical text to the UMLS metathesaurus: the MetaMap program. In: Proceedings of the AMIA Symposium, p. 17. American Medical Informatics Association, Bethesda (2001).

[2] Atzeni, M., Recupero, D.R.: Deep learning and sentiment analysis for human-robot interaction. In: The Semantic Web: ESWC 2018 Satellite Events - ESWC 2018 Satellite Events, Heraklion, Crete, June 3-7, 2018. Revised Selected Papers, pp. 14-18 (2018).

[3] Berners-Lee, T., Chen, Y., Chilton, L., Connolly, D., Dhanaraj, R., Hollenbach, J., Lerer, A., Sheets, D.: Exploring and analyzing linked data on the semantic web. In: Proceedings of the 3rd International Semantic Web User Interaction Workshop, SWUI 2006, Athens (2006).

[4] Big Data and Analytics for Infectious Disease Research, Operations, and Policy: Proceedings of a Workshop (2016).

[5] Colin, P., Karthik, P.G., Preteek, J., Peter, Y., Kunal, V.: Multiple ontologies in healthcare information technology: motivations and recommendation for ontology mapping and alignment. In: Proceedings of International Conference on Biomedical Ontologies, New York, pp. 367-369 (2011).

[6] Decap, D., Reumers, J., Herzeel, C., Costanza, P., Fostier, J.: Halvade: scalable sequence analysis with mapreduce. Bioinformatics 31(15), 2482-2488 (2015).

[7] Dessì, D., Cirrone, J., Recupero, D.R., Shasha, D.E.: Supernoder: a tool to discover over-represented modular structures in networks. BMC Bioinf. 19(1), 318:1-318:12 (2018).

[8] Garcia-Barbero, M., Gröne, O.: Trends in integrated care reflections on conceptual issues. World Health Organization, Copenhagen, EUR/02/5037864 (2002).

[9] Robert A. Berenson, Peter J. Pronovost, and Harlan M. Krumholz, Achieving the Potential of Health Care Performance Measures (Washington: Urban Institute, 2013).

[10] Patient Protection and Affordable Care Act, Public Law 111-148 (March 23, 2010), as modified by the Health Care and Education Reconciliation Act of 2010, Public Law 111-152 (March 30, 2010), Title 1, Subtitle D, Section 1311.

[11] Jerry Cromwell, Michael Trisolini, Gregory Pope, Janet Mitchell, and Leslie Greenwald, Pay for Performance in Health Care: Methods and Approaches (Research Triangle Park, NC: Research Triangle International, 2011).

[12] Elizabeth McGlynn, Stephen Asch, John Adams, et al., "The Quality of Care Delivered to Adults in the United States," The New England Journal of Medicine 348, no. 26 (June 2003): 2,641.

[13] Fayers PM, Machin D. Quality of life: assessment, analysis and interpretation. Chichester: Wiley, 2000.

[14] Raghupathi, W., and Raghupathi, V. Big data analytics in healthcare: promise and potential. Health information science and systems 2, 1 (2014), 3.

[15] O’Driscoll, Aisling, Jurate Daugelaite, and Roy D. Sleator. "'Big data', Hadoop and cloud computing in genomics." Journal of biomedical informatics 46.5 (2013): 774-781.

[16] S. Packiyam,et al. "Aids Detection System Using Big Data Analysis." IJANA (International Journal of Advanced Networking \& Applications), (2017):105-109. 